2. Beveridge J, Johnson S 1949 Determination of phospholipid phosphorus. Can J Res Sect E27:159

3. Bondurant S, Miller D 1962 A method for producing surface active extracts of mammalian lungs. J Appl Physiol 17:167

4. Cassin S 1980 Role of prostaglandins and thromboxanes in the control of the pulmonary circulation in the fetus and newborn. Sem Perinatol 4:101

5. Challis J, Dilley S, Robinson J, Thorburn G 1976 Prostaglandins in the circulation of the fetal lamb. Prostaglandins 11:1041

6. Challis J, Osathanondh R, Ryan K, Tulchinsky D 1974 Maternal and fetal plasma prostaglandin levels at vaginal delivery and caesarian section. Prostaglandins 6:281

7. Colacicco G, Basu M, Ray A, Wittner M, Roenbaum R 1977 Effects of prostaglandins $E_{2}$ and $F_{2 \propto}$ on lecithin biosynthesis by cultured lung cells. Prostaglandins 14:283
8. Folch J, Lees M, Sloan-Stanley G 1957 A simple method for the isolation and purification of total lipids from animal tissues. J Biol Chem 226:497

9. Kadowitz P, Chapnick B, Joiner P. Hyman A 1975 Influence of inhibitors of prostaglandin synthesis on the canine pulmonary vascular bed. Am J Physiol 229:941

10. Kulovich M, Hallman M, Gluck L 1979 The lung profile. Am J Obstet Gynecol 135:57

11. Leffler C. Tyler T, Cassin S 1978 Effect of indomethacin on pulmonary vascular response to ventilation of fetal goats. Am J Physiol 234:H346

12. Oyarzun M, Clements M 1978 Vetilation, prostaglandins and autonomic mediators in regulation of pulmonary alveolar surfactant content in rabbits. Am Rev Respir Dis 117:879

13. Scarpelli EM, Kumar A, Doyle C, Clutario B 1981 Functional anatomy and volume-pressure characteristics of immature lungs. Respir Physiol 45:25

\title{
Growth-related Changes in Oxygen Uptake and Heart Rate during Progressive Exercise in Children
}

\author{
DAN M. COOPER*, DANIEL WEILER-RAVELL, BRIAN $J$. WHIPP, AND \\ KARLMAN WASSERMAN \\ Division of Respiratory Phsyiology and Medicine, Department of Medicine, and Department of Pediatrics, \\ University of California, Los Angeles, School of Medicine, Harbor-UCLA Medical Center, \\ Torrance, California 90509
}

\begin{abstract}
Summary
Although body size and muscle mass increase considerably during growth in children, certain aerobic responses to exercise appear to be regulated so that the delivery of oxygen to muscle is maintained at optimized levels. We proposed that the relationship between oxygen uptake, $\left(\mathrm{VO}_{2}\right)$ and heart rate $(\mathrm{HR})$ was one of the regulated responses. We further hypothesized that the increase in $\mathrm{V}_{2}$ per increase in $\mathrm{HR}$ during progressive exercise would differ in subjects of different size, but when normalized to body weight would be constant since changes in muscle mass are highly correlated to changes in body mass. To test this, we performed a cross-sectional study of 107 normal children, 50 girls and 57 boys ranging in age from 6 to 17 years. The protocol consisted of a continuously increasing work rate on a cycle ergometer, to the limit of the child's tolerance (ramp forcing function). Gas exchange was measured breath-by-breath for the determination of $\dot{\mathrm{VO}}_{2}$, and heart rate was measured beat-by-beat. We used linear regression techniques to determine $M$, the slope, and $B$, the $y$ intercept of the equation: $\dot{\mathrm{VO}}_{2}=M \times \mathbf{H R}-B$. In both boys and girls, $M$ increased significantly with body weight, but when normalized for body weight $(M / \mathrm{kg})$, there was no systematic change with increasing weight or age, the mean value being $0.33 \pm 0.10 \mathrm{ml} / \mathrm{min} / \mathrm{kg}$ (SD). The mean value for the boys was $0.37 \pm 0.10$ which was significantly greater than that of the girls $(0.29 \pm 0.08, p<0.01)$. Using allometric equations, we found $M, B$, and the $\mathrm{O}_{2}$-pulse $\left(\dot{V}_{\mathrm{O}_{2}} / \mathrm{HR}\right)$ at a heart rate of 140 beats/min and at the anaerobic threshold, all scaled in direct

Received July 8, 1983; accepted February 7, 1984.

Reprint requests may be addressed to Dan M. Cooper, M.D. A-15 Annex, Harbor-UCLA Medical Center. Torrance, CA 90509.

* Senior Investigator of the American Heart Association, Greater Los Angeles Affiliate.
\end{abstract}

proportion to body weight (i.e., to 1.0 power of body weight). We conclude that during growth, the output of the heart is closely tied to the size of the muscles so that delivery of oxygen during exercise is maintained at optimized levels from early in childhood.

\section{Abbreviations}

$\dot{V}_{\mathrm{O}_{2}}$, oxygen uptake

$\dot{V}_{\mathrm{O}_{2}}$ max, maximum oxygen uptake

$A T$, anaerobic threshold

HR, heart rate

$\mathrm{SV}$, stroke volume

$(a-\bar{v}) \mathrm{O}_{2}$, arteriovenous oxygen content difference

We have recently demonstrated that certain aerobic parameters of exercise appear to be highly regulated as body weight changes during growth in children. The work efficiency and the response time for $\dot{\mathrm{V}}_{2}$ following the onset of exercise are independent of body size, whereas the $\mathrm{V}_{2} \max$ and the $A T$ increase in direct proportion to body weight (6). Moreover, the $\dot{\mathrm{VO}}_{2}$ increases linearly with work rate in both adults and children $(6$, 19 ) indicating that as more muscle units are activated, the flow of oxygen is optimized so that a unique work efficiency is maintained at virtually all levels of energy demand. In addition, other investigators have shown that the relationship between $\mathrm{VO}_{2}$ and $\mathrm{HR}$ is linear during progressive exercise in children, and that the $\mathrm{VO}_{2}-\mathrm{HR}$ relationship changes in a systematic way as children grow $(1,9)$.

Based on these observations and on the concept that the cellular milieu must be maintained within a narrow range of temperature and $\mathrm{pH}$, we proposed that the $\mathrm{V}_{2}-\mathrm{HR}$ relationship 


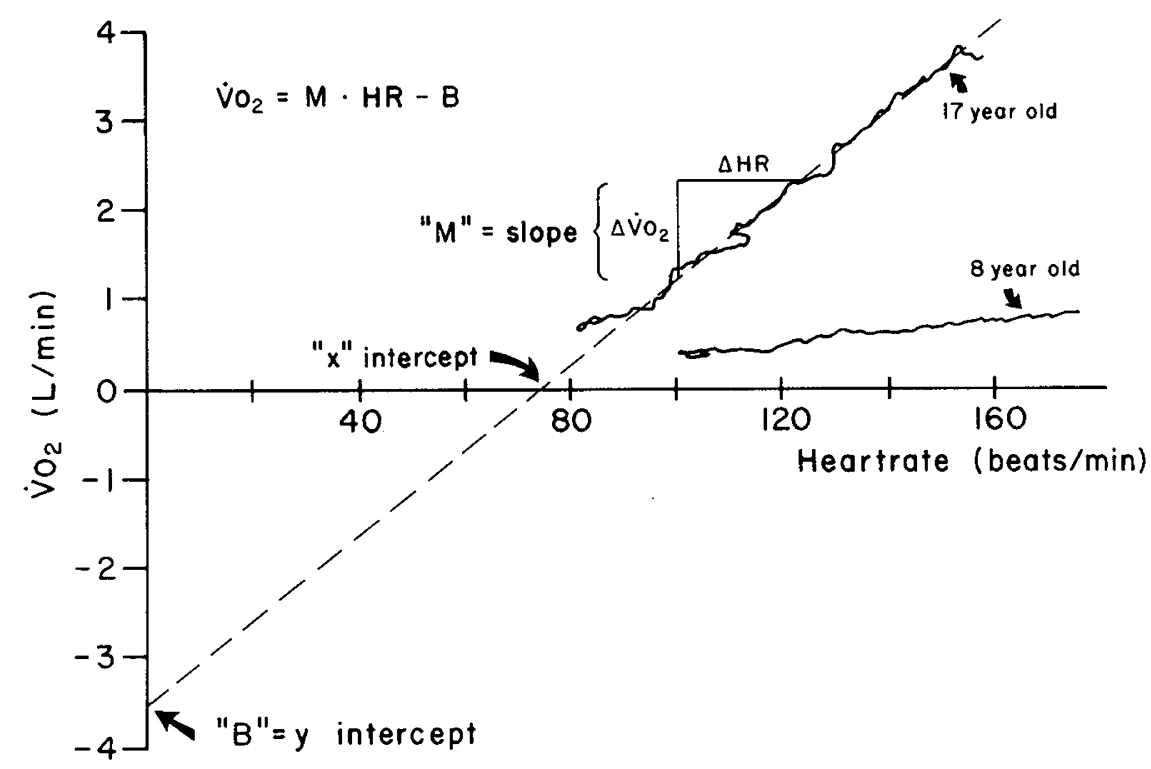

Fig. 1. The relationship between $\dot{\mathrm{V}}_{2}$ and $\mathrm{HR}$ during progressive exercise in an 8- and 17-year-old subject. Linear regression techniques were used to evaluate the linear portion of the $\mathrm{V}_{2}-\mathrm{HR}$ relationship (see text). The subjects were compared by calculating 1) the slope of the line, $M$ $\left.\left(\Delta \dot{\mathrm{VO}}_{2} / \Delta \mathrm{HR}\right) ; 2\right)$ the $y$ intercept, $B$; and 3$)$ the $x$ intercept, as illustrated.

during exercise was regulated throughout growth in order to optimize oxygen transport to working muscle cells. The increase in $\mathrm{V}_{2}$ per heart beat as exercise progresses would be related to factors such as stroke volume and hemoglobin concentration. Consequently, in a given individual during a progressive exercise test, the $\mathrm{VO}_{2}-\mathrm{HR}$ relationship tends to be constant (Fig. 1), but is likely to vary with the size of the subject. We hypothesized that the increase in the $\dot{\mathrm{V}}_{2}$ per increase in heart beat during exercise would differ in subjects of different size, but when normalized to body weight (an estimate of muscle mass) would be constant. To test this, we examined the slope $(M)$, and the $y$ intercept $(B)$ of the $\dot{\mathrm{VO}}_{2}-\mathrm{HR}$ relationship as shown in Figure 1 and as given by the equation:

$$
\dot{\mathrm{V}}_{2}=M \times \mathrm{HR}-B
$$

We used a cross-sectional study and examined the relationship between $\mathrm{VO}_{2}$ and $\mathrm{HR}$ during progressive exercise in a large number of normal children. Recent work has shown that the response of $\dot{\mathrm{V}}_{2}$ and HR to progressive exercise is complex, and that nonlinearities often occur in the transition between work rates or at the onset of exercise: the kinetic phase of $\mathrm{O}_{2}$ uptake (Fig. 2) (11). Furthermore, above the $A T$, since some ATP is produced anaerobically, $\dot{\mathrm{VO}}_{2}$ may not reflect all of the mechanical work done by the exercising subject. We therefore restricted the analysis of the $\dot{\mathrm{V}}_{2}-\mathrm{HR}$ relationship in progressive exercise to the region which followed the early dynamic phase and up to the $A T$.

Accurate, well standardized measurements of muscle mass are not currently available. However, existing evidence suggests that, during childhood, the ratio of muscle to body mass increases slightly with age in boys and decreases slightly in girls, remaining relatively constant when considering all children (12); thus, the changes in body mass (weight) reflect the changes in muscle mass. We therefore hypothesized that $M$ should increase in proportion to body size in such a way that the ratio of $M$ to body weight would be independent of the child's size.

\section{MATERIALS AND METHODS}

Population. All subjects were volunteers obtained through local schools, community organizations, and members of the hospital staff. We excluded children with obesity, those with a history of chronic disease of any organ system, or children who were not allowed to participate in normal physical education programs at

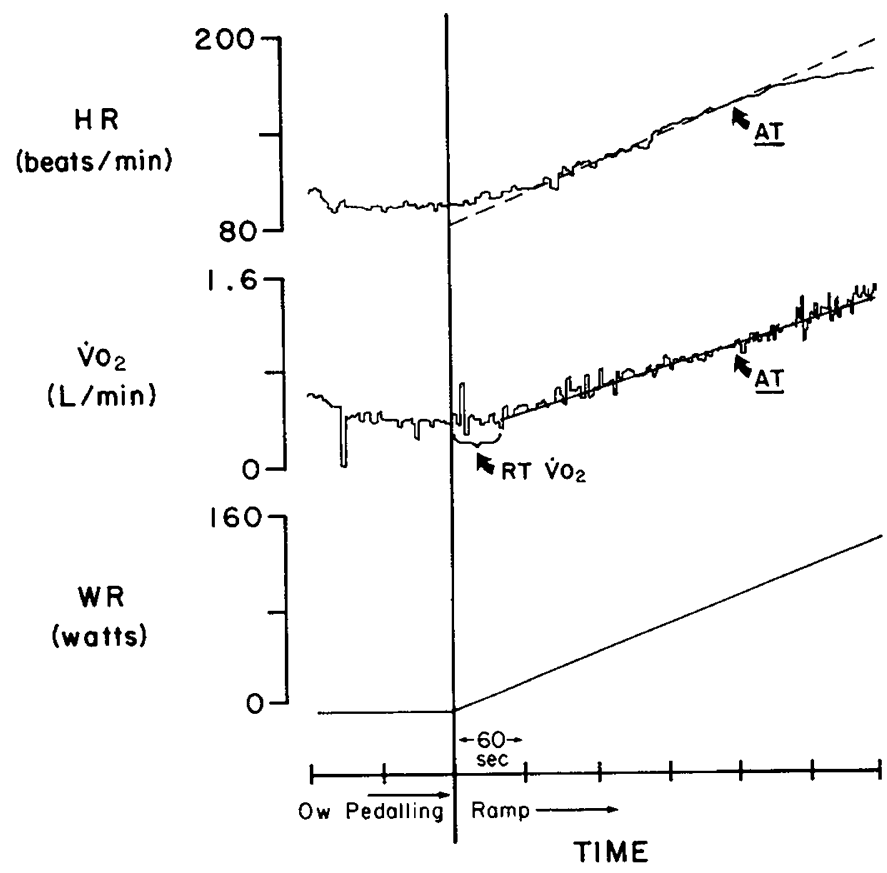

Fig. 2. $\mathrm{HR}$ and $\mathrm{V}_{2}$ response to a ramp protocol in a 10-year-old girl. The input used in these studies consisted of a ramp work rate forcing function (as shown). Following an initial lag (response time for $\mathrm{VO}_{2}$ ), $\mathrm{V}_{2}$ increases linearly with work rate. The $\mathrm{VO}_{2}-\mathrm{HR}$ lines in this study were analyzed in the region following the response time for $\dot{\mathrm{V}}_{2}$ up to the $A T$. The $A T$ was determined noninvasively by gas exchange techniques as described in the text. Note the decrease in the slope of the HR response after the AT in this subject.

school. No attempt was made to select children who were particularly active; i.e., we did not recruit through physical education or sports programs.

107 children, 57 boys and 50 girls, ranging in age from 6 to 17 years, comprised the study population. 114 children were originally tested of whom five were excluded because the anaerobic threshold could not be determined by gas exchange techniques, and two were excluded because of technically poor recording of HR. Age, weight, and height profiles of our study 
Table 1. Anthropometric profile of the study population (means

\begin{tabular}{lccc}
\multicolumn{4}{c}{ $\pm S D)$} \\
& $\begin{array}{c}\text { Girls } \\
(n=50)\end{array}$ & $\begin{array}{c}\text { Boys } \\
(n=57)\end{array}$ & $\begin{array}{c}\text { All children } \\
(n=107)\end{array}$ \\
\hline Age $(\mathrm{yr})$ & $12 \pm 3$ & $12 \pm 4$ & $12 \pm 3$ \\
Weight $(\mathrm{kg})$ & $43 \pm 14$ & $45 \pm 18$ & $44 \pm 16$ \\
Height $(\mathrm{cm})$ & $148 \pm 19$ & $152 \pm 23$ & $150 \pm 21$ \\
\hline
\end{tabular}

population are provided in Table 1 . The children were predominantly of the middle socioeconomic class. $86 \%$ of the subjects were Caucasian; the remainder consisted of Oriental, Hispanic, and Black children. This project was approved by the Human Subjects Committee of Harbor-UCLA Medical Center. Informed consent was obtained from each child and guardian prior to participation.

Exercise protocol. Testing was done usually in the late afternoon (after school) or at various times on weekends. The subjects were told that they would be doing one hard exercise test on a special bicycle and that they would feel like they were riding up a hill. We told them to try as hard as they could to get to the "top of the hill." The protocol consisted of a ramp forcing function (21) utilizing an electronically braked cycle ergometer (Godart). Subjects began by cycling at 0 watt (unloaded) work rate for 3-4 $\mathrm{min}$ as a warm-up phase. Work rate was then continuously incremented in a linear ramp pattern. An example of the $\mathrm{V}_{2}-\mathrm{HR}$ relationship with a ramp protocol is shown in Figure 2.

A suitable slope of the ramp (the increase in work rate per minute) was determined for each child based on our own initial studies and the previous demonstrations that the $A T$ determined by gas exchange techniques is independent of the ramp slope (8). In general, for children from 6 to 9 years of age, the ramp slope was $10 \mathrm{~W} / \mathrm{min}$; from $10-13,15 \mathrm{~W} / \mathrm{min}$; and from $14-17,20 \mathrm{~W} /$ min. For certain adolescents who were deemed to be quite fit by history, ramp slopes as high as $40 \mathrm{~W} / \mathrm{min}$ were chosen. The mean time for the ramp (not counting the warm-up) was $9 \mathrm{~min}$. The children were instructed to raise their hand when they could not continue, and upon this signal, the work rate was reduced to $0 \mathrm{~W}$.

In an additional 17 subjects, the relationship between $\dot{\mathrm{V}}_{2}$ and heart rate was assessed by measuring the steady-state values at two separate work rates: $0 \mathrm{~W}$ and $80 \%$ of the $A T$.

The children maintained as constant a pedaling rate as possible between 50 and $70 \mathrm{rpm}$ during the test with a pedaling rate meter in full view and a metronome which could be activated at the discretion of the investigator. A servomechanism in the electronic braking system of the ergometer maintained the input work rate independent of pedal frequency to an accuracy of $1 \%$ within this range.

Measurement of gas exchange and $H R$. The subjects breathed through a low resistance valve (Hans Rudolph). For children less than 12 years old, a 40-ml deadspace valve was used and for those 12 and above, a 90-ml valve. Inspiratory and expiratory airflows were measured by two pneumotachographs (Fleisch No. 3 ), attached to the inspiratory and expiratory ports of the breathing valves, and by two variable reluctance manometers (Validyne, MP45). The expiratory pneumotachograph was maintained at a constant temperature of $37^{\circ} \mathrm{C}$ by a thermal feedback device. This system was calibrated before each session by inputting known volumes of room air at various mean flows and flow profiles. Respired $\mathrm{PO}_{2}$ and $\mathrm{PCO}_{2}$ were determined by mass spectrometry (Perkin-Elmer MGA 1100) from a sample drawn continuously from the mouthpiece at $1 \mathrm{ml} / \mathrm{sec}$. Precision-analyzed gas mixtures were used for calibration of the mass spectrometer. The system was found to be stable throughout the period of the study. Heart rate was measured beat-by-beat using three anterior chest leads and the EKG was in continuous view via a high persistence ECG oscilloscope (Hewlett-Packard).

The electrical signals from these devices underwent analog-to- digital conversion (Hewlett-Packard No. 1050) for the on-line, breath-to-breath determination of $\mathrm{O}_{2}$ uptake ( $\mathrm{VO}_{2}$ STPD), $\mathrm{CO}_{2}$ output ( $\left.\dot{\mathrm{V}}_{\mathrm{CO}_{2}} \mathrm{STPD}\right)$, expired ventilation ( $\left.\dot{\mathrm{V}}_{\mathrm{E}} \mathrm{BTPS}\right)$; respiratory exchange ratio $R\left(\dot{\mathrm{V}}_{\mathrm{CO}_{2}} / \dot{\mathrm{VO}}_{2}\right)$; ventilatory equivalent for oxygen and for carbon dioxide $\left(\dot{\mathrm{V}}_{\mathrm{E}} / \dot{\mathrm{VO}}_{2}, \dot{\mathrm{V}}_{\mathrm{E}} / \mathrm{VCO}_{2}\right)$; end-tidal partial pressures of oxygen and carbon dioxide $\left(\mathrm{P}_{\mathrm{ET}} \mathrm{O}_{2}, \mathrm{P}_{\mathrm{ET}} \mathrm{CO}_{2}\right)$ and $\mathrm{O}_{2^{-}}$ pulse $\left(\grave{\mathrm{V}}_{2} / \mathrm{HR}\right)$ as previously described (4). The data from each test were displayed on line (Beckman R711 Dynagraph) and stored on digital tape for subsequent analysis.

Analysis of gas exchange data: $\dot{V} \mathrm{O}_{2} \max$. We took the $\dot{\mathrm{VO}}_{2} \max$ as the highest $\dot{\mathrm{VO}}_{2}$ achieved by the subject.

$A T$. The $A T$ indicates the onset of metabolic acidosis during exercise $(19,20)$ and was determined from gas exchange data by finding the oxygen uptake at which $\dot{\mathrm{V}}_{\mathrm{E}} / \dot{\mathrm{V}}_{2}, \mathrm{P}_{\mathrm{ET}} \mathrm{O}_{2}$, and $R$ increase (hyperventilation with respect to $\mathrm{O}_{2}$ ) without an increase in $\dot{\mathrm{V}}_{\mathrm{E}} / \dot{\mathrm{VCO}}_{2}$ or a decrease in $\mathrm{P}_{\mathrm{ETCO}}$. Hyperventilation with respect to $\mathrm{O}_{2}$ without concomitant hyperventilation for $\mathrm{CO}_{2}$ occurs during buffering of a metabolic acid by $\mathrm{HCO}_{3}^{-}$.

Analysis of $\dot{V O}_{2}-H R$ relationship. As shown in Figure 2 and Equation 1, we analyzed the relationship of $\mathrm{VO}_{2}$ to $\mathrm{HR}$ by considering the data only in the region bounded by the dynamic phase of oxygen uptake kinetics at the onset of exercise and the $A T$. As demonstrated previously in these subjects (6), the response time of $\mathrm{VO}_{2}$ averaged $43 \pm 15 \mathrm{sec}$ (SD), and the $A T$ occurred at a mean of $60 \pm 9 \%$ of the $\mathrm{VO}_{2}$ max.

While $M$ is defined as $\Delta \dot{V}_{2} / \Delta \mathrm{HR}$, the $\mathrm{O}_{2}$ pulse is defined as $\dot{\mathrm{V}}_{2} / \mathrm{HR}$. The $\mathrm{O}_{2}$-pulse can be considered in terms of $\dot{\mathrm{VO}}_{2}$, stroke volume, the arteriovenous $\mathrm{O}_{2}$ content difference, and $\mathrm{HR}$ by using the Fick equation:

$$
\dot{\mathrm{V}}_{2}=\mathrm{SV} \times \mathrm{HR} \times(a-\bar{v}) \mathrm{O}_{2}
$$

which is equivalent to:

$$
\dot{\mathrm{VO}}_{2} / \mathrm{HR}=\mathrm{SV} \times(a-\bar{v}) \mathrm{O}_{2}
$$

Dividing through Equation 1 by $\mathrm{HR}$ gives:

$$
\dot{\mathrm{V}}_{2} / \mathrm{HR}=M-B / \mathrm{HR}
$$

Consequently, the $\mathrm{O}_{2}$-pulse changes hyperbolically as a function of $\mathrm{HR}$ (Equation 4) approaching $M$ asymptotically (Fig. 3). Furthermore, the rate of change of the $\mathrm{O}_{2}$-pulse as a function of increasing $\mathrm{HR}$ can be found as the first derivative of Equation 4 with respect to $\mathrm{HR}$ and is given by the expression $B / \mathrm{HR}^{2}$ which allows comparison of the characteristic $\mathrm{O}_{2}$-pulse curve in subjects of different size.

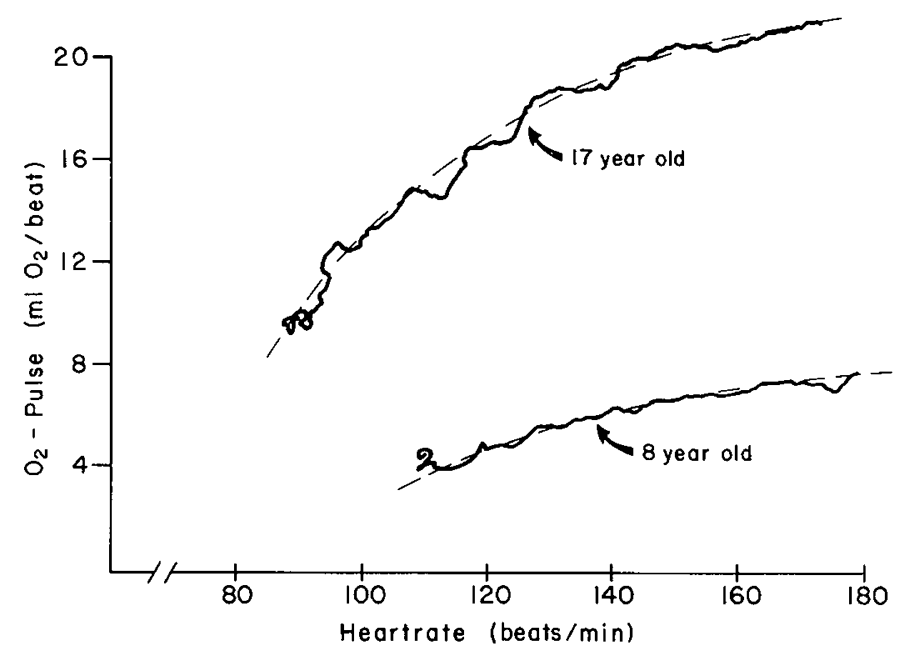

Fig. 3. The $\mathrm{O}_{2}$-pulse $\left(\mathrm{VO}_{2} / \mathrm{HR}\right)$ as a function of heart rate during progressive exercise in an 8-and 17-year-old subject. The $\mathrm{O}_{2}$-pulse curve considered this way can be described by a hyperbola (dashed lines) in which the asymptote is $M$, the slope of the $\dot{\mathrm{VO}}_{2}-\mathrm{HR}$ relationship (see text). The first derivative of this function with respect to $\mathrm{HR}, B / \mathrm{HR}^{2}$, can be used to characterize the curves in children of different sizes. 
Examples of the $\mathrm{O}_{2}$-pulse as a function of heart rate are shown for a 8-year-old and a 17-year-old in Figure 3. The $\mathrm{O}_{2}$-pulse was considered at several different points during exercise. It was measured at a heart rate of 140 beats/min which represents a midrange of exercise for both small and large children, this heart rate being achieved after the dynamic phase at the onset of exercise but before the $A T$ in almost all subjects. In addition, we measured the $\mathrm{O}_{2}$-pulse at the $A T$.

Scaling metabolic rate to body size. In characterizing the relationship between body size and metabolic function, comparative physiologists have used allometric equations which have the form:

$$
Y \infty \text { mass }^{c}
$$

in which $Y$ represents metabolic rate or function such as $\mathrm{O}_{2}$ pulse, mass represents body weight, and $c$ is the scaling factor. Body weight is most commonly used for body size because neither cell size nor body density varies significantly with body size among different mammalian species. Thus, the body mass is an estimate of the number of cells, and scaling metabolic function to body weight can be used to identify how cell function changes with differences in body size $(10,14,16)$. Allometric equations are solved by taking the log-log transform and using linear regression techniques to find the slope (the scaling factor) of the following relationships:

$$
\log Y \infty c \times \log \text { mass }
$$

A scaling factor equal to 1 indicates that the metabolic rate represented by $Y$ increases in direct proportion to body weight. Statistical analysis. Standard techniques of linear regression were used. Differences between slopes of regression equations were assessed using the $t$ test. Comparison of multiple means was done by analysis of variance and modified $t$ test by the method of Bonferroni (18). Results are presented as mean $\pm \mathrm{SD}$.

\section{RESULTS}

Relationship between $\dot{V} O_{2}$ and $H R$. We chose to limit the analysis of the $\dot{\mathrm{VO}}_{2}-\mathrm{HR}$ relationship to the region below the $A T$ as we had previously noted nonlinearities at higher work rates. In this study, there was no change in $M$ above the $A T$ in only $36 \%$ of the subjects; in $23 \%$ it increased; in $41 \%$ the slope decreased. Within our selected range, the mean correlation coefficient between $\mathrm{VO}_{2}$ and heart rate for the group as a whole was

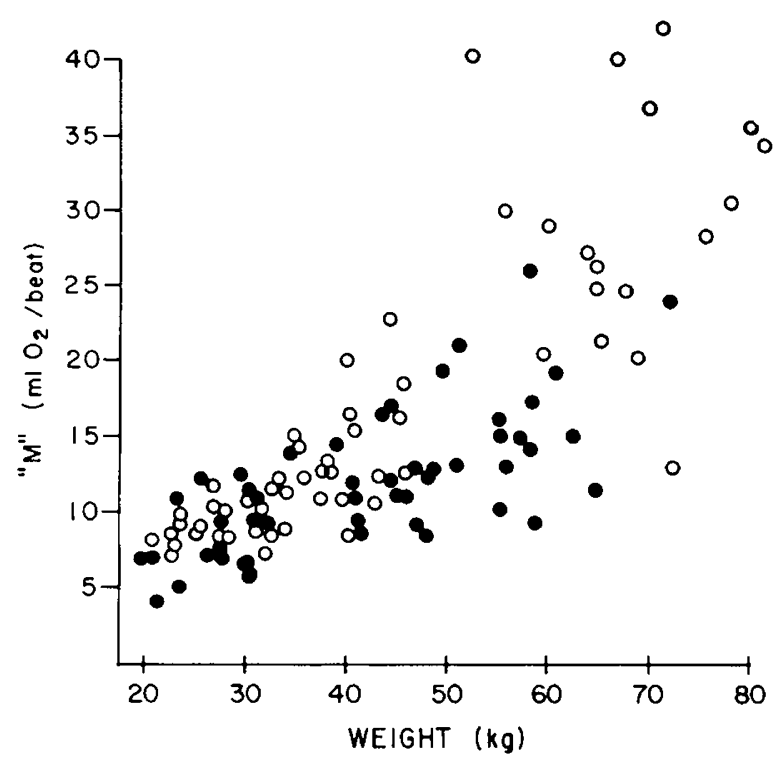

$0.68 \pm 0.21$ (using linear regression techniques). However, these values were not normally distributed, the mode being between 0.8 and 0.9 . The lowest correlation coefficients were found in the younger children, and tended to increase with age $(r=0.55$ for the correlation coefficient as a function of age). This occurred for several reasons: first, the range of $\mathrm{VO}_{2}$ was much smaller in the younger subjects; thus, the effect of "respiratory noise" on the gas exchange measurements was proportionally greater. Second, some younger children would "start and stop" exercise during the test period resulting in a somewhat greater degree of heart rate variation.

In the 17 subjects tested with the steady-state protocols, there was no significant difference between the $\Delta \mathrm{VO}_{2} / \Delta \mathrm{HR}$ and those obtained from the ramp test $(p<0.01)$.

Slope. In both boys and girls, $M$ increased significantly with body weight and height (Fig. 4, Table 2). The slope was significantly greater in boys than in girls $(p<0.01$ by $t$ test). However, when the slope was normalized to body weight $(\mathrm{M} / \mathrm{kg})$, we found no systematic change in the population as a whole with increasing weight or age (Fig. 5). The mean value for the boys was $0.37 \pm$ $0.10 \mathrm{ml} / \mathrm{min} / \mathrm{kg}$ and was significantly greater than the value of the girls, $0.29 \pm 0.08(p<0.01)$. For the group as a whole, the mean value was $0.33 \pm 0.10$.

The scaling factor for $M$ as a function of body weight did not differ significantly from 1.0 (Table 3 ). In contrast, the scaling factor for $M$ as a function of body height is 3.0 which is consistent with our previous finding in these children that height scales to body weight to the 0.33 power (6).

$H R$ and $\dot{V} O_{2}$ intercept. $B$, the $\dot{\mathrm{VO}}_{2}$ intercept ( $y$ intercept), increased significantly with body weight in both boys and girls; however, it was not as highly correlated as $M$ (Table 2). Moreover, $B$ increased more rapidly with body weight in boys than it did in girls. When normalized for body weight, $B$ was not significantly correlated to age $(r=0.19)$ and its scaling factor for the population as a whole did not differ significantly from 1.0 (Table 3).

The HR intercept ( $x$ intercept) of the $\mathrm{V}_{2}-\mathrm{HR}$ relationship is found by dividing $M$ by $B$. The HR intercept was not correlated to body weight $(r=0.04)$. For the study population as a whole, the mean of the HR intercept was $67 \pm 16$ beats $/ \mathrm{min}$. For the boys, the mean was $68 \pm 16$ beats/min, and for the girls, $66 \pm$ 16 beats/min. There was no significant difference in the values between the boys and the girls.

Figure 6 summarizes the $\dot{\mathrm{VO}}_{2}-\mathrm{HR}$ relationships in children of

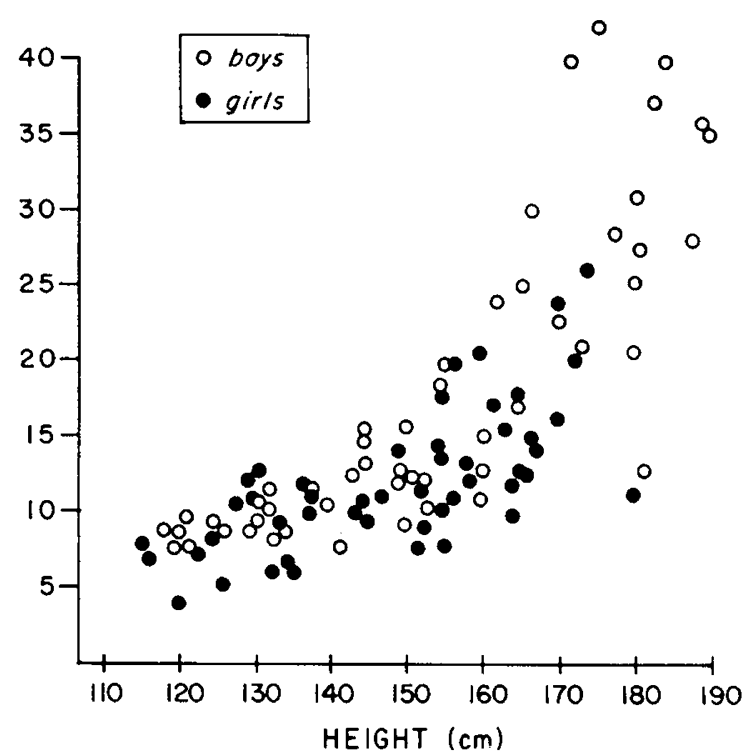

Fig. 4. The slope $M$ of the $\mathrm{VO}_{2}$-HR relationship as a function of body weight (left panel) and height (right panel) in the study population. The slope increased systematically with increasing body size, but more rapidly in boys than in girls. Equations for the slope as a function of weight are given in Tạble 2. Using height, the linear regression equation was: $M=0.32(\mathrm{Ht})-33.9, r=076$, for the whole study population. 
Table 2. The slope $(M)$ and the $y$ intercept $(B)$ of the $\dot{V} \mathrm{O}_{2}-\mathrm{HR}$ relationship, and the $\mathrm{O}_{2}$-pulse as functions of body weight ( $\mathrm{kg}$ ) in the study population $(Y=a \times($ body weight $)+c)$

\begin{tabular}{|c|c|c|c|c|c|c|c|}
\hline \multirow[b]{2}{*}{$Y$} & & \multirow[b]{2}{*}{$a$} & \multicolumn{2}{|c|}{$\begin{array}{l}95 \% \text { confidence } \\
\text { interval }\end{array}$} & \multirow[b]{2}{*}{$c$} & \multirow[b]{2}{*}{$r$} & \multirow[b]{2}{*}{$S y \cdot x$} \\
\hline & & & Lower & Upper & & & \\
\hline \multirow[t]{3}{*}{$M\left(\mathrm{ml} \mathrm{O}_{2} /\right.$ beat $)$} & All subjects & 0.40 & 0.34 & 0.47 & -2.98 & 0.77 & 5.32 \\
\hline & Girls & $0.24^{*}$ & 0.16 & 0.31 & 2.01 & 0.68 & 3.44 \\
\hline & Boys & 0.47 & 0.39 & 0.55 & -3.97 & 0.84 & 5.44 \\
\hline \multirow[t]{3}{*}{$B\left(\mathrm{ml} \mathrm{O}_{2} / \mathrm{min}\right)$} & All subjects & 28.4 & 21.6 & 35.2 & -207.1 & 0.63 & 584.5 \\
\hline & Girls & $18.3^{*}$ & 10.0 & 26.6 & 53.3 & 0.53 & 399.8 \\
\hline & Boys & 32.5 & 22.6 & 42.4 & -242.0 & 0.66 & 664.0 \\
\hline \multirow{3}{*}{$\mathrm{O}_{2}$-pulse $(A T)\left(\mathrm{ml} \mathrm{O}_{2} /\right.$ beat $)$} & All subjects & 0.19 & 0.16 & 0.21 & -0.57 & 0.84 & 1.94 \\
\hline & Girls & $0.11^{*}$ & 0.09 & 0.13 & 1.57 & 0.81 & 1.07 \\
\hline & Boys & 0.22 & 0.19 & 0.24 & -0.98 & 0.93 & 1.61 \\
\hline \multirow{3}{*}{$\mathrm{O}_{2}$-pulse $(140$ beats $/ \mathrm{min})$} & All subjects & 0.19 & 0.18 & 0.21 & -1.03 & 0.82 & 2.20 \\
\hline & Girls & $0.11^{*}$ & 0.09 & 0.12 & 1.62 & 0.70 & 1.48 \\
\hline & Boys & 0.23 & 0.22 & 0.25 & -1.69 & 0.92 & 1.76 \\
\hline
\end{tabular}

* Value significantly lower than the boys $(p<0.05)$.

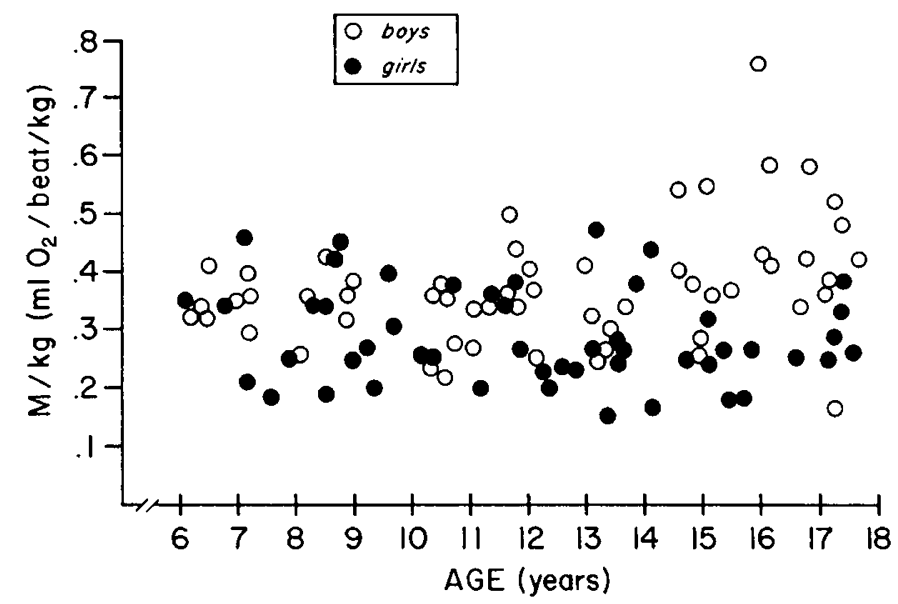

Fig. 5. The slope $M$ of the $\mathrm{V}_{2}$-HR relationship normalized for body weight $(M / \mathrm{kg})$ as a function of age. There was no systematic change for $M / \mathrm{kg}$ in the population as a whole, but values for boys were significantly higher than for girls.

Table 3. Scaling factors for the slope $(M)$, and the $y$ intercept (B) of the VO-pulse as functions of body weight

\begin{tabular}{|c|c|c|c|c|c|}
\hline & & \multirow{2}{*}{$\begin{array}{l}\text { Scaling } \\
\text { factor }\end{array}$} & \multicolumn{2}{|c|}{$\begin{array}{c}95 \% \\
\text { confidence } \\
\text { interval }\end{array}$} & \multirow[b]{2}{*}{$r$} \\
\hline & & & Lower & Upper & \\
\hline \multirow[t]{3}{*}{$M\left(\mathrm{ml} \mathrm{O}_{2} /\right.$ beat $)$} & All subjects & 1.07 & 0.88 & 1.20 & 0.79 \\
\hline & Girls & 0.83 & 0.59 & 1.07 & 0.71 \\
\hline & Boys & 1.15 & 0.98 & 1.31 & 0.88 \\
\hline \multirow[t]{3}{*}{$B(\mathrm{ml} \mathrm{O} / \mathrm{min})$} & All subjects & 1.12 & 0.83 & 1.42 & 0.60 \\
\hline & Girls & 1.02 & 0.53 & 1.51 & 0.52 \\
\hline & Boys & 1.16 & 0.83 & 1.50 & 0.69 \\
\hline \multirow{3}{*}{$\begin{array}{r}\mathrm{O}_{2} \text {-pulse }(A T) \\
\left(\mathrm{ml} 0_{2} / \text { beat }\right)\end{array}$} & All subjects & 0.96 & 0.85 & 1.08 & 0.85 \\
\hline & Girls & 0.73 & 0.58 & 0.88 & 0.82 \\
\hline & Boys & 1.09 & 0.99 & 1.20 & 0.95 \\
\hline \multirow{3}{*}{$\begin{array}{c}\mathrm{O}_{2} \text {-pulse }(140 \\
\text { beats } / \mathrm{min}\end{array}$} & All subjects & 1.00 & 0.85 & 1.14 & 0.81 \\
\hline & Girls & 0.71 & 0.51 & 0.91 & 0.73 \\
\hline & Boys & 1.16 & 1.01 & 1.31 & 0.91 \\
\hline
\end{tabular}

different sizes (weighing 20,50, and $80 \mathrm{~kg}$ and representing children aged 6,12 , and 17 years, respectively) utilizing $M$ and $B$ calculated for each weight group from the linear regression equations obtained in our study population.

Oxygen-pulse. The $\mathrm{O}_{2}$-pulse at the $A T$ and at a heart rate of

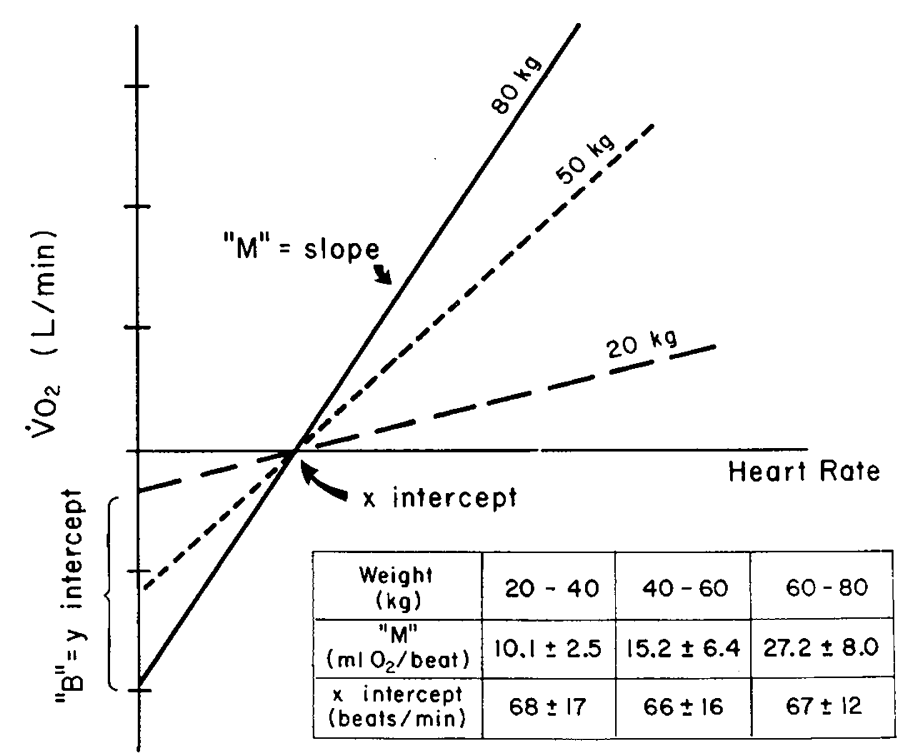

Fig. 6. Schematic representation of the $\dot{\mathrm{V}}_{2}-\mathrm{HR}$ relationship in children weighing 20,50 , and $80 \mathrm{~kg}(6,12$, and 17 years old, respectively) derived from our data. Note that the $x$ intercept is virtually unchanged despite the differences in the size of the children.

140 beats/min increased significantly with weight in both boys and girls (Table 2, Fig. $7 A$ ). The slope of these relationships in girls was significantly lower than in the boys (Table 2). For the whole study population, the scaling factor for the $\mathrm{O}_{2}$-pulse at the $A T$ and at 140 beats/min as a function of weight did not differ from a factor of 1.0 (Table 3 ).

The $\mathrm{O}_{2}$-pulse at 140 beats/min was highly correlated to the subject's $A T, r=0.88$ (Fig. $7 B$ ). In contrast to the findings of $\mathrm{O}_{2}$-pulse as a function of body weight (Table 2 ), the regression slope for the $\mathrm{O}_{2}$-pulse as a function of $A T$ did not differ significantly between the boys (slope $=7.2 \times 10^{-3}$ ) and the girls (slope $\left.=5.8 \times 10^{-3}\right)$.

\section{DISCUSSION}

Consistent with our hypothesis, we found that the relationship between $\mathrm{VO}_{2}$ and heart rate when normalized to body weight did not change with growth in a large group of children (Fig. 5). The data demonstrate that both $M$ and $B$ scale in direct proportion to body weight (Table 3); thus, not only does the amount of oxygen extracted per heart beat during exercise increase in direct proportion to body mass, but the shape of the $\mathrm{O}_{2}$-pulse curve as exercise progresses (Eq. 4), its rate of change at a particular heart 

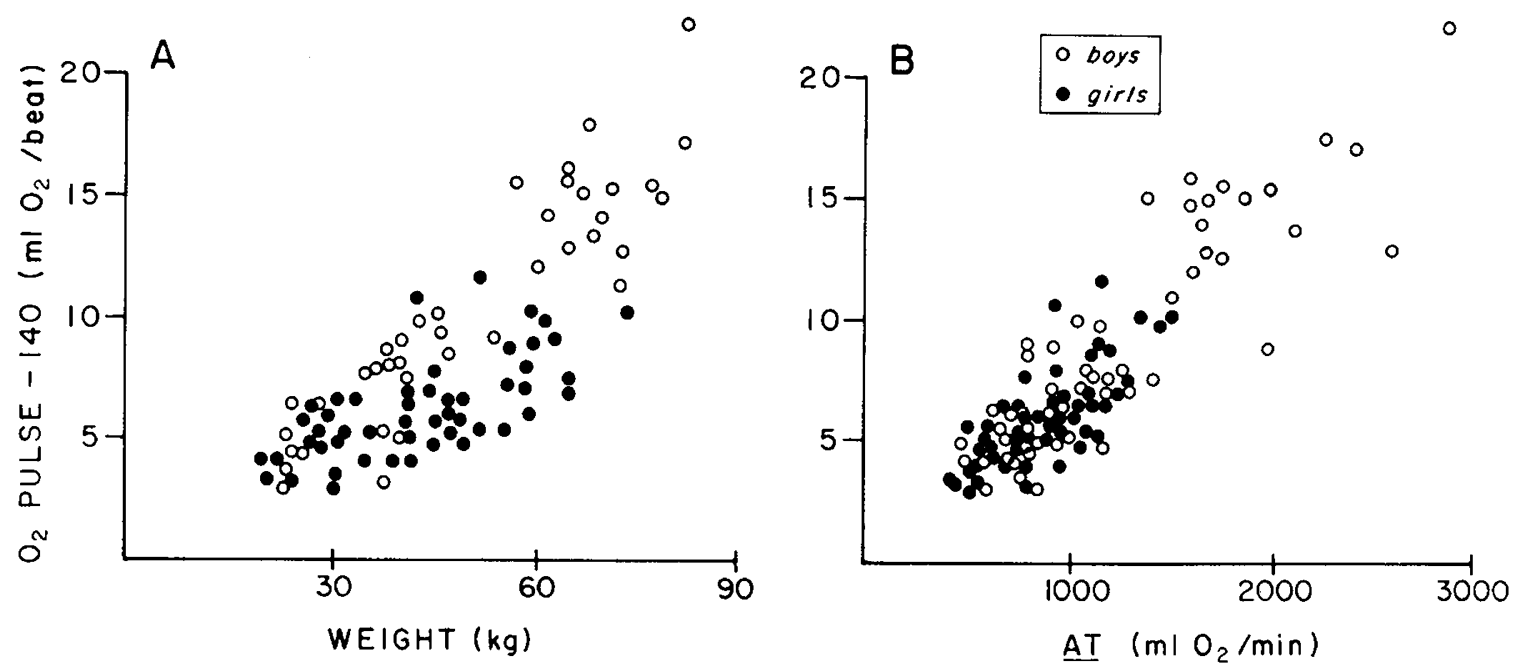

Fig. 7. $A$, the $\mathrm{O}_{2}$-pulse at a heart rate of 140 also increased with body weight in boys and girls. The regression slope for the boys was significantly higher than for the girls (Table 2). $B$, the $\mathrm{O}_{2}$-pulse at a heart rate of 140 increased systematically with $A T$; however, there was no significant difference between the regression slopes of the boys and girls.

rate $\left(B / \mathrm{HR}^{2}\right)$, is also directly proportional to body mass. These data suggest that, during growth, the cardiorespiratory and musculoskeletal systems are integrated so that oxygen flow during exercise is "optimized" to meet the energy requirements of the muscle cells despite the changes in body size.

Certain inferences about growth-related changes in cardiac output can be made from our measurements of $\mathrm{VO}_{2}$ and heart rate. Direct measurements of stroke volume and $(a-\bar{v}) \mathrm{O}_{2}$ during exercise are rarely available in normal children; thus, the ability to indirectly quantify these variables from noninvasive measurements assumes additional importance. At rest, the $(a-\bar{v}) \mathrm{O}_{2}$ is the same in adults and children (15); thus, the $\mathrm{O}_{2}$-pulse is directly proportional to the stroke volume and can be used to compare the relative magnitudes of the stroke volume in children as they grow (Eq. 3). Previous workers have found that the resting $\mathrm{O}_{2^{-}}$ pulse scales to body weight to the power of 1 , implying that the resting stroke volume increases in direct proportion to body weight (2). Data from other investigators suggest that during exercise the $(a-\bar{v}) \mathrm{O}_{2}$ in children differs from that in adults only at higher work rates where it may be slightly larger (3). We found that the $\mathrm{O}_{2}$-pulse during moderate levels of exercise, at the $A T$ and at a heart rate of 140 beats $/ \mathrm{min}$, also scales in direct proportion to body weight (Fig. $7 A$; Table 3), and this implies that the stroke volume increase (which occurs early in exercise) is proportionally similar in subjects of widely different size.

As shown in Figures 4 and 5 and Table 2, the differences between the exercise responses of the boys and girls become evident above the age of 12-13 years corresponding, in general, to the onset of puberty. There is evidence that the proportion of muscle mass to body weight is higher in boys than in girls, and that these differences become more prominent at puberty (13). If an accurate measurement of muscle mass could be made, a difficult determination in vivo, then the magnitude of the slope per kg muscle would likely be less different between the boys and girls. Furthermore, iron deficiency anemia is more common among teenage girls than boys (5), and this, too, may affect $\mathrm{O}_{2}$ transport during exercise, thereby resulting in a relative tachycardia for a given exercise $\dot{\mathrm{V}}_{2}$.

We reasoned that if the $\dot{\mathrm{VO}}_{2}-\mathrm{HR}$ response were correlated to a more functional index of muscular oxygen utilization than body weight alone (the $A T$, for example), then the differences between the boys and girls, seen so clearly when body weight was used, would be lessened. In Figure $7 \mathrm{~B}$, the $\mathrm{O}_{2}$-pulse at 140 beats/min is plotted as a function of the $A T$, and, as expected, the gender differences were virtually eliminated. Nonetheless, there remains a great deal of variation in the $\mathrm{VO}_{2}-\mathrm{HR}$ response within each group at any particular weight. Consistent with this are the findings of Davies and Sargeant (7) who showed improvement in $\dot{\mathrm{VO}}_{2}$ max without apparent increases in muscle mass in subjects who underwent a program of training a single leg. Thus, while muscle size itself is a major determinant of the $\mathrm{VO}_{2}-\mathrm{HR}$ response during growth in children, other factors such as mitochondrial and capillary density, or levels of oxidative enzymes, also are likely to play an important role in the development of the cardiorespiratory response to exercise.

As shown in Figure 6, the slope of the $\mathrm{V}_{2}-\mathrm{HR}$ relationship in children of different sizes can be schematized to demonstrate the increasing slopes as weight increases. However, as the slope increases, the $x$ intercept appears to be unchanged and is independent of body size in normal children. Is there any physiologic significance to this imaginary heart rate when $\mathrm{VO}_{2}$ is zero? One speculation is that the cardiovascular system, similar to other hydraulic systems, needs to be "primed" at some heart rate and stroke volume (i.e., cardiac output). The $x$ intercept might, therefore, reflect elastic properties of the heart and blood vessels, and would be expected to become abnormal in various disease states.

The concept of "symmorphosis," recently introduced by Taylor and Weibel (17) as a model of how the structure of oxygen delivery systems differ in mammals of widely different sizes, holds that "animals are reasonably built," in that the formation of structural elements is regulated to satisfy but not exceed the requirements of the functional system. However, they conceived of the "requirements" of the system only in terms of maximal levels. We propose that dynamic characteristics of the system, those occurring in the transition between different metabolic requirements, may be equally as important constituents of the system's requirements since the demands imposed on most creatures in daily life rarely require maximal metabolic responses; rather, they vary in intensity and duration.

In this context, our finding that the dynamic relationship between $\dot{\mathrm{VO}}_{2}, \mathrm{HR}$, and body weight are constant during growth in children identifies a set of "regulated" parameters of cardiorespiratory function during growth and can be used to quantify the relationship between structure and function in normal children. Moreover, oxygen flow may become abnormal in congenital diseases of the heart or in childhood diseases involving the lung and blood vessels. The measurement of the regulated parameters of exercise during growth, as proposed in this paper, may prove useful in understanding the consequences of such impairment on growth and development of the oxygen uptake and delivery systems in children. 
Acknowledgments. The authors thank Dr. Andrew Husczuk for his insightful criticism of this manuscript.

\section{REFERENCES}

1. Astrand P-O 1952 Experimental Studies of Physical Working Capacity in Relation to Sex and Age. Muskgaard, Copenhagen, $171 \mathrm{pp}$

2. Astrand P-O, Rodahl K 1977 Textbook of Work Physiology, ed 2. McGrawHill Book Co., New York, pp 367-388

3. Bar-Or O, Shepard RJ, Allen CJ 1971 Cardiac output of 10- to 13-year-old boys and girls during submaximal exercise. J Appl Physiol 30:219

4. Beaver WL, Lamarra N, Wasserman K 1981 Breath-by-breath measurement of true alveolar gas exchange. J Appl Physiol Respir Environ Exercise Physiol $51: 1662$

5. Cook JD, Finch CA. Smith NJ 1976 Evaluation of the iron status of a population. Blood 48:449

6. Cooper DM. Weiler-Ravell D, Whipp BJ, Wasserman K 1984 Aerobic parameters of exercise as a function of body size during growth in children. J Appl Physiol Respir Environ Exercise Physiol 53:628

7. Davies CTM, Sargeant JA 1975 Effects of training on the physiological responses to one- and two-leg work. J Appl Physiol 38:377

8. Davis JA, Whipp BJ, Lamarra N, Huntsman DJ, Frank MH, Wasserman K 1982 Effect of ramp slope on determination of aerobic parameters from the ramp exercise test. Med Sci Sports Exercise 14:339

9. Godfrey S, Davies CTM, Wozniak E, Barnes CA 1971 Cardiorespiratory response to exercise in normal children. Clin Sci 40:419

10. Kleiber M 1961 The Fire of Life. John Wiley and Sons, New York, pp 177 225

11. Lamarra N 1982 Ventilatory control, cardiac output, and gas-exchange dynamics during exercise transients in man. Ph.D. dissertation, Dept of Engineering University of California, Los Angeles

12. Malina RM 1978 Growth of muscle tissue and muscle mass. In: Falkner $F$ Tanner JM (eds) Human Growth, vol 2. Plenum Press, New York, pp 273 294

13. Marshall WA 1978 Puberty. In: Falkner F, Tanner JM (eds) Human Growth vol 2. Plenum Press, New York, pp 141-178

14. Schmidt-Nielsen K 1977 Problems of scaling: locomotion and physiologica correlates. In: Pedley TJ (ed) Scale Effects in Animal Locomotion. Academic Press, London, $560 \mathrm{pp}$

15. Sproul A, Simpson E 1964 Stroke volume and related hemodynamic data in normal children. Pediatrics 33:912

16. Taylor CR, Maloiy GMO, Weibel ER, Langman VA, Kamau JMZ, Seeherman JH, Heglund NC 1981 Design of the mammalian respiratory system. III. Scaling maximum aerobic capacity to body mass: wild and domestic mammals. Respir Physiol 44:25

17. Taylor CR. Weibel ER 1981 Design of the mammalian respiratory system. I Probl $m$ and strategy. Respir Physiol 44:1

18. Wallensiein S, Zucker CL. Fleiss JL 1980 Some statistical methods useful in circulation research. Circ Res 47:1

19. Wasserman K, Whipp BJ, Davis JA 1981 Respiratory physiology of exercise metabolism. gas exchange, and ventilatory control. Int Rev Physiol 23:180

20. Wasserman K. Whipp BJ, Koyal SN, Beaver WL 1973 Anaerobic threshold and respiratory gas exchange during exercise. J Appl Physiol 35:236

21. Whipp BJ, Davies JA. Torres F, Wasserman K 1981 A test to determine parameters of aerobic function during exercise. J Appl Physiol Respir Environ Exercise Physiol 50:217

\title{
The Relationship between the Branched Chain Amino Acids and Their $\alpha$-Ketoacids in Maple Syrup Urine Disease
}

\author{
SELMA E. SNYDERMAN, FRED GOLDSTEIN, CLAUDE SANSARICQ, AND \\ PATRICIA M. NORTON* \\ Department of Pediatrics, New York University Medical Center, New York, New York 10016
}

\begin{abstract}
Summary
Plasma branched chain amino acid levels and their respective ketoacid analogues were determined in seven maple syrup urine disease patients ranging in age from $12 \mathrm{~h}$ to 12 years. One hundred one pairs were analyzed. There was a high degree of correlation between the amino acid and its ketoacid analogue at every amino acid level. The coefficient of correlation $(0.84)$ was highest for leucine- $\alpha$-ketoisocaproic acid. The ratio of ketoacid analogue to amino acid, $(0.87)$, was also the greatest for leucine. The close correlation implies that adequate monitoring for therapy can be accomplished by the use of the technically simpler and more rapid determination of the plasma branched chain amino acids.
\end{abstract}

Received August 22, 1983; accepted February 7, 1984.

Correspondence may be addressed to Selma E. Snyderman, M.D., Department of Pediatrics, New York University Medical Center, 550 First Avenue, New York, New York 10016.

Supported by Grant MCJ-000317, Office for Maternal and Child Health, Bureau of Community Health Services, Health Service Administration, Department of Health, Education, and Welfare.

* Deceased.
Maple syrup urine disease (branched chain ketoacidemia) in its classical form is a devastating disease. Untreated, it results in rapid neurologic deterioration and death in the first weeks of life. It is the consequence of a defect in the metabolism of the branched chain amino acids. The first step, transamination, takes place normally, but there is failure of the second step, oxidative decarboxylation. As a result, there is accumulation of both the branched chain amino acids and their ketoacid analogues in a number of body fluids. One of the still unexplained findings in this disease has been the much greater abnormality of the plasma leucine level than that of the other two branched chain amino acids. This is of special importance because the appearance of clinical symptoms can be most closely related to the degree of elevation of the plasma leucine level; we have been able to document this relationship in our treatment of over 20 cases. In addition, study of animal tissue homogenates and brain slices has demonstrated the toxic effect of $\alpha$-ketoisocaproic acid, the derivative of leucine. Inhibition of 1-glutamic acid decarboxylase (24), depressed oxygen utilization (8), and inhibition of pyruvate oxidation have been reported (1).

Very few quantitative determinations of the individual branched chain keto acids in the plasma have been performed 